\title{
THE KNIT ON DEMAND SUPPLY CHAIN
}

\author{
Jonas Larsson ${ }^{1}$, Joel Peterson ${ }^{1,2}$, Heikki Mattila² \\ 'University of Borås, Swedish School of Textiles, S-50190, Borås, Sweden \\ ${ }^{2}$ Tampere University of Technology, Materials Sciences, P.O. Box 589, FI-33101 Tampere, Finland \\ e-mail: joel.peterson@hb.se, jonas.larsson@hb.se
}

\begin{abstract}
:
As customers' tastes become more differentiated, so must companies' offerings evolve. The demand for variety may soon become unmanageable, and several companies are addressing this trend by adopting a system of mass customization. One project, Knit on Demand, has been conducted by the Swedish School of Textiles in close collaboration with a knitting company and a retailer of tailored fashion in Stockholm. Production and sales of customized products pose logistical challenges for the companies involved, including the one-piece flow through almost the entire supply chain and the demand for short lead times in an otherwise slow environment, adding to the cost of manufacturing mass customized garments. Customization has logistical benefits such as minimised inventory; hence, high inventory turnover and the possibility of fast response to meet customer demand. The Knit on Demand concept can be considered as leagile because it comprises both lean and agile components. It is lean in the manufacturing stage upstream and agile downstream to better respond to customer demand on the market.
\end{abstract}

\section{Keywords:}

Mass customization, supply chain management, fashion logistics, knitwear, demand driven, agile, lean, leagile.

\section{Introduction}

In Western society there is an abundance of choice. As long as your body fits the standard sizes, you can find any shirt, pair of pants, sweater, or jacket you could wish for. However, abounding products lead to an excess of choice in the market. A clear majority of apparel buying is done up-front, ahead of season, with long lead times based on forecasts. Often the forecasts are wrong and there is no demand for the products, which have to be marked down at the end of the season [1].

This is good for customers, who will not have to pay full price, but bad for the fashion companies. Cerruti and Harrison suggest that the reason for the overstocking in the market is the short lifecycle of fashion garments, and that fashion companies are trying to respond to the diverse customer demand by attempting to offer everything [2]. It may also be due to long lead times caused by outsourced production [1]. Yet another reason for overproduction could be that it is less expensive to have one extra product in stock than to lose a customer due to limited inventory. Whatever the reasons, given all the extra garments for which no one is willing to pay full price, unsold goods are a significant challenge.

An ideal strategy would be to produce only what the customer wants. This would require either a state-of-the-art forecasting tool with 100 percent accuracy or on-demand production. Since no such forecasting tool exists, the only option is to produce according to demand. In order to test this system, the Swedish School of Textiles collaborated with a knitwear producer, Ivanhoe $A B$, and a tailored fashion retailer, SOMconcept $A B$, on a project called Knit on Demand. The aim was to "demonstrate a production method for knitwear that may strongly influence the ability of the fashion industry to meet new demands for agility in customer relations" [3].

The result of the project is a mass customization business concept in which, within certain limitations, customers can design or customize their own knitted garments, which are then produced at Ivanhoe AB in Gällstad in southern Sweden. Sales began at SOMconcept in Stockholm in September 2009. Pine [4] describes mass customization as the ability to produce individualized garments at near mass production efficiency. It both addresses the market's surplus and allows companies to reduce lost sales $[5,6]$. Although few traditional fashion companies have explored mass customization, new businesses such as Tailor Store AB and SOMconcept $A B$ have appeared. Mass customization may not be an answer to the fashion industry's short lifecycle and abundance of products; it may also address other social trends, such as the "rise of the creative class" [7]. Moreover, for those customers who seem to be looking for experiences when they go shopping, designing a unique garment may be such an experience $[8,9]$.

The supply chain of a mass customization system differs somewhat from that of mass production. First, it reacts to true customer demand and not to forecasts. It also has a welldefined customer order decoupling point (CODP) after which no changes can be made, and it operates as a one-piece flow in which every product has a dedicated customer waiting for it at the end of the process. CODP has been defined as the point at which the physical product is linked to the customer's order. 
Previous work on mass customization in the fashion industry has mostly studied how customers prefer to buy customized products and how they experience the customization process $[10,11]$. There is little literature on the supply chains of mass customized fashion in general, and on mass customized knitwear in particular.

This paper presents the Knit on Demand concept from a supply chain perspective, with a focus on the customization and fit of the garment, manufacturing, and delivery logistics. It also assesses whether the original idea of the Knit on Demand project "to meet new demands for agility in customer relations" has been fulfilled.

The Council of Supply Chain Management Professionals (CSCMP) defines supply chain management as follows [12]:

Supply chain management encompasses the planning and management of all activities involved in sourcing and procurement, conversion, and all logistics management activities. Importantly, it also includes coordination and collaboration with channel partners, which can be suppliers, intermediaries, third party service providers, and customers. In essence, supply chain management integrates supply and demand management within and across companies.

We selected this definition because it encompasses all supply chain activities and also includes the customer.

\section{Theoretical framework}

\section{Supply Chain Processes}

Lean is a production concept that considers the use of resources for anything other than the creation of value for the customer to be waste that should be eliminated. Agility is the ability to react quickly to unpredictable changes in market demand. Supply chains for mass customized products must respond in a timely manner to diverse customer demands. Companies engaged in mass customization such as Nike, SOMconcept, and Tailor Store offer their customers billions of style combinations with a promised lead time of about three weeks, depending on their available production capacity. Such supply chain capabilities are often referred to as agile [13-15]. An agile supply chain reacts to actual customer demand, rather than relying on the skewed predications of forecasting tools [13]. Not only does it respond to such demand, but it thrives in a volatile marketplace as well [16]. The concept of agility, originally applied to flexible manufacturing systems, has extended beyond production to encompass entire business organizations [17].

As in the lean concept, agile systems focus on customer value in all processes and are flexible and responsive to demand. According to Harrison and van Hoek, four parameters define the agile supply chain [14]. First, it should be market responsive. Second, it should be viewed as a network rather than a chain. Third, its partners should work to create synergies among their business capabilities. Fourth, the supply chain should use information and communication technology to share information in a virtual network. The benefit of these processes is not necessarily cost; it may be flexibility [17]. However, lean philosophies overlap with those of mass customization and emphasize waste reduction, a steady flow of material and information, and production that is determined by customer needs [18].

Leanness and agility do not conflict, but in fact support each other [19]. They can be combined in a leagile strategy where the supply chain is lean up to the CODP. At the decoupling point-when the customer orders and pays for the garmentthe system becomes agile and can respond to actual customer demand. In a trade-off between flexibility and productivity, one must consider the driving force behind the business concept, i.e., economies of scope.

A one-piece flow is characteristic of supply chains of mass customized garments. According to Miltenburg [20], the one-piece flow is best suited for U-shaped pull production systems paced by tact time. Products that are highly varied can be turned out in medium quantities in cells that progress evenly. One-piece flow is flexible and has a high quality output and short throughput times. It also greatly reduces waste and decreases total lead time, since no products are stored between processes [18].

One purpose of the Knit on Demand project was to meet new demands for agility in the manufacture of fashion products.

\section{Mass customization}

The notion of mass customization appeared in the late 1980s. It seeks to provide unique products to meet a customer's individual needs $[4,21,22]$. Gilmore and Pine describe four types of customization: adaptive, cosmetic, transparent, and collaborative [8]. In adaptive customization the company provides customers with standard parts and lets them do the customization themselves. Lego is an example of such a system. Cosmetic customization only leaves room for changes to the surface of the product, such as breweries offering customized labels for the identical beer. Transparent customization offers changes in the product's properties but not its appearance, as in identical-looking pairs of eyeglasses with differing lens strengths. Collaborative customization is the highest form, regarded by purists as "true" customization. It requires a close dialogue in which the customer articulates his or her needs, e.g., the tailoring of shirts, shoes, and suits. Salvador et al. [24] divide mass customized products into two types of supply chains, one for hard customization and one for soft customization. Hard customization is what Gilmore and Pine [23] refer to as collaborative customization. Soft customization includes adaptive and transparent customization, with cosmetic falling somewhere in between. Hard customization is characterized by rapid response to customer demand and a high level of customization, whereas soft customization has longer lead times and lower customizability [24].

Postponement and modularization are often central to mass customization supply chains [25]. Postponing value-adding 
activities to the point where the demand can be estimated more accurately can reduce the risk of unsold products [26]. Rudberg and Wikner refer to this point in mass customization systems as the CODP [27]. Modularity and product platforms are also characteristic of such processes [24]. Muffatto and Roveda [28] describe a product platform as "a set of subsystems and interfaces intentionally planned and developed to form a common structure from which a stream of derivative products can be efficiently developed and produced". Modularity and postponement aim to keep product commonality as far downstream along the supply chain as possible and to separate product customization from the manufacturing of standard components [25].

\section{$\underline{\text { Knitting technologies }}$}

The various flat knitting techniques currently available all build on the same principle: two knitting beds in an inverted V-position. The most basic machines, called cut \& sew, can knit panels, which must later be cut into garment pieces. Fully fashioned and integral knitting machines are somewhat more advanced and are able to shape-knit the garment pieces and add pockets, thereby reducing time and waste of yarn. The most advanced complete garment machines knit the entire garment in one piece, eliminating the need for cutting and sewing $[29,30]$. Figure 1 illustrates the different available knitting technologies.

Knitting techniques affect how the production process is designed with the goal of achieving high efficiency and fulfilling the promised lead time. Each technique has particular advantages for mass customization.

\section{Methods}

This article uses a case study method. Case studies are powerful tools for mapping real life situations in which the boundaries between the object studied and its environment are blurred [31], as in supply chains. Researchers also welcomed methods other than strictly quantitative ones, the kind most commonly encountered in logistics research [32,33]. We triangulated the results of two case studies we had conducted in order to arrive at conclusions that were reliable [34].

The first case study was conducted in the spring of 2010, after sales had been underway for seven months [35]. Its purpose was to map the Knit on Demand supply chain. It used the "value stream mapping" technique that was developed to identify and eliminate waste in production flow [36]. The study begins with the customer entering the store and purchasing a garment. It then tracks the order to the CODP---when the order becomes a garment---and ends when delivery is made to the customer.

The second case study was conducted in December of 2010 [37]. Each purchase of a customized knitted garment was analyzed in terms of measurement customization. These measurements were then compared to Sweden's standard size tables. In total there were 37 orders from 30 customers. The study period included all garments purchased from SOMconcept between September 2009 and December 2010. The project ended in December 2010 due to capacity constraints of the manufacturer. This article does not consider the purchasing and delivery of raw materials nor strategic planning, since the raw material for the customized knitwear is taken from the same inventory that supplies ordinary production.

Cut and sew

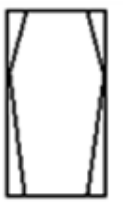

шщше

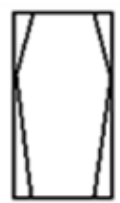

шщш)

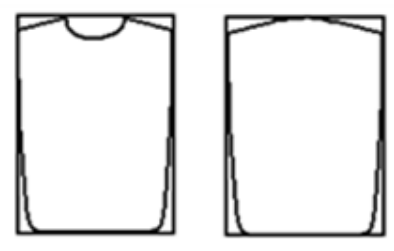

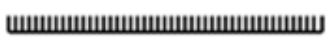

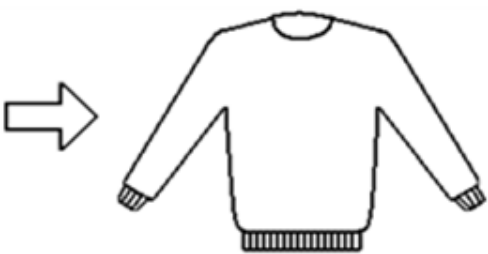

Fully fashion/Integral knitting
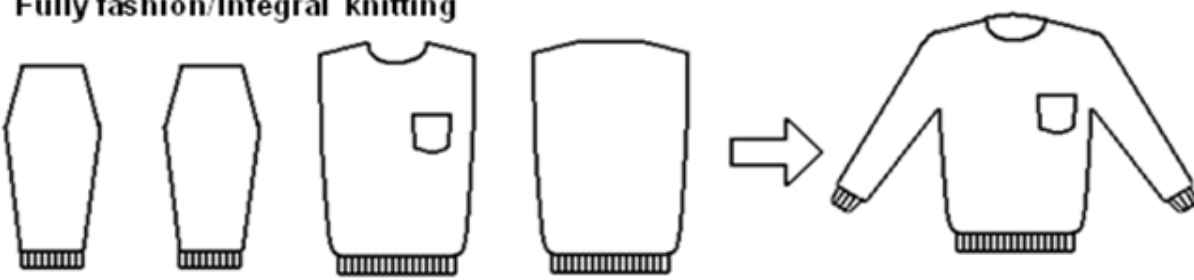

\section{Complete garment}

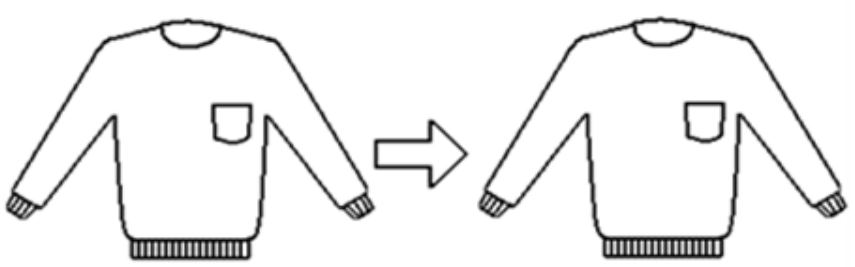

Figure 1. Different knitting technologies. 


\section{Results and discussion}

This chapter presents the order fulfilment process, from order entry to the final delivery of the product.

Figure 2 illustrates the supply chain and the flow of materials, finished products, and information in the Knit on Demand concept.

Knit on Demand is an "on-demand" supply chain in which manufacturing does not begin until there is a customer order although much preparation has already taken place. Raw materials such as yarn, accessories, and threads have been bought and are stored at the manufacturing plant, and the design system and order sheets have been developed. Because the supply chain is rather short, it can respond quickly to customer demand.

\section{$\underline{\text { The customization process }}$}

The system begins when a customer enters the store and decides to buy a customized knitted garment. He or she is guided through the steps of the design process (Figure 3 ) by a tailor and allowed to change four parameters of a garment: model, fit, colour, and details.
These four parameters are further subdivided, resulting in 16 design steps in total. It is a manual system, that is, the customer receives no visual feedback other than examining fabric swatches and garments in the store. The tailor must ensure that the customer understands what the end result will look like in order to avoid dissatisfaction. When a design is completed, it is entered in a spreadsheet and sent to the manufacturer by e-mail, and the producer confirms the order. Customers can choose from six different models (Figure 4), 16 colours, stripes, contrasting fabrics (for the neck plate), and various buttons.

Each garment is made-to-measure using a system in which standard size garments are used as gauges and changed according to customer preferences. The sleeves and body measurements are altered in $2 \mathrm{~cm}$ increments, with the maximum adjustment being plus or minus $8 \mathrm{~cm}$. If a very tall, slim customer wants to buy a garment in a narrow size, small is used as a base pattern and the body and sleeves are lengthened accordingly. Table 1 describes how a customer's measurement data are modified from a standard size.

Forty-one percent of customers changed only one measurement. The customers who chose to alter the sleeves lengthened them an average of $1.8 \mathrm{~cm}$, or one length interval. Customers who changed only the body measurements decreased the length on

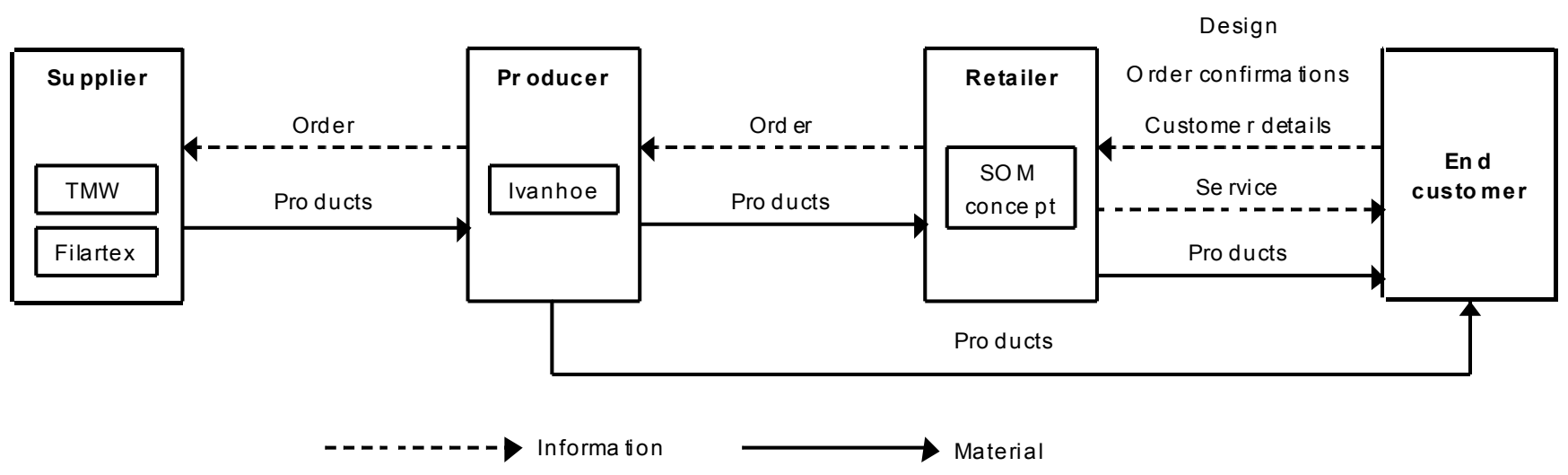

Figure 2. The Knit on Demand supply chain.

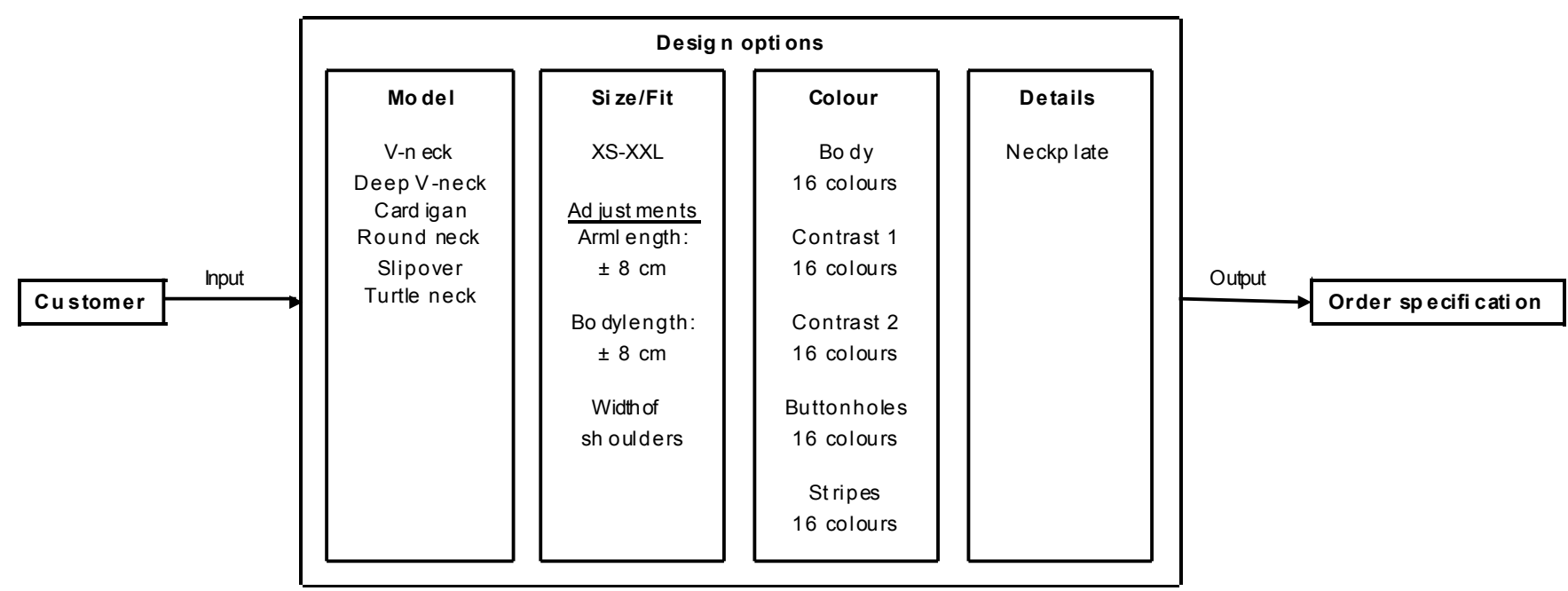

Figure 3. Design options. 

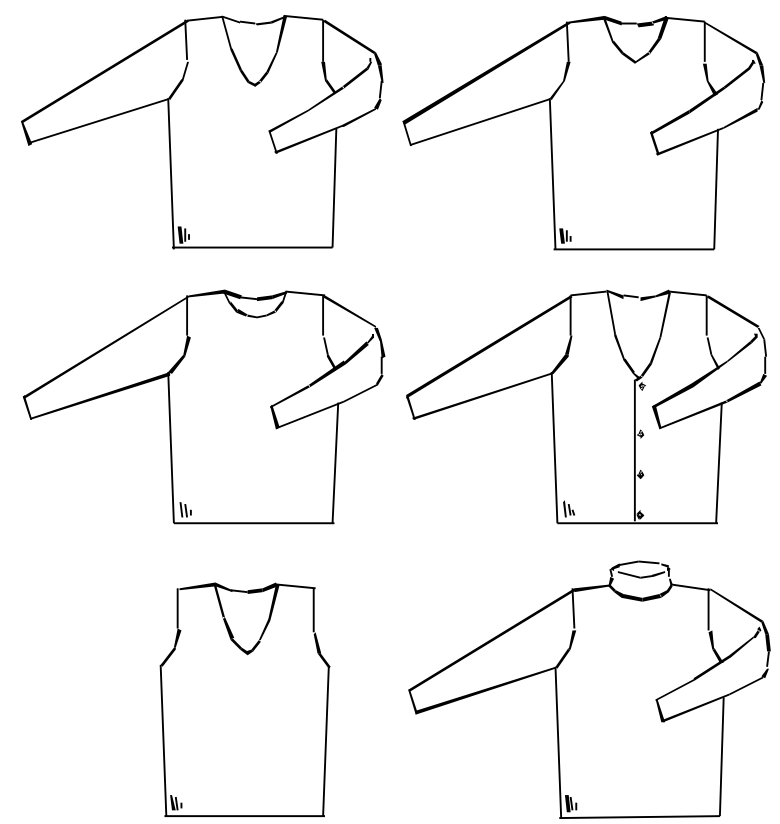

Figure 4. Garment styles.

Table 1. Average measurment alteration.

\begin{tabular}{|c|c|c|c|c|}
\hline Type of change & Average (cm) & \multicolumn{2}{c|}{ Standard deviation (cm) } \\
\hline Only sleeves & \multicolumn{2}{|c|}{1.8} & \multicolumn{2}{c|}{2.0} \\
\hline Only body & \multicolumn{2}{|c|}{-0.3} & Sleeves & \multicolumn{2}{c|}{ Body } \\
\hline \multirow{2}{*}{$\begin{array}{c}\text { Both sleeves } \\
\text { and body }\end{array}$} & Sleeves & Body & 2.51 & 2.76 \\
\cline { 2 - 5 } & 3.84 & 3.84 & \\
\hline
\end{tabular}

average by $0.3 \mathrm{~cm}$. Thirty-eight percent of customers changed both the body and sleeve measurements. They lengthened the garments on average by almost two intervals. Half of the customers mentioned above could not be accommodated by standard clothing sizes: no mass producer manufactured garments that fit them. Twenty-one percent of customers made no changes at all.

Shoppers buy customized garments for fit, design, and quality. Many have not owned a sweater that actually fits them for years. The garments they are accustomed to buying have been too short, too slim, or too wide; finally owning an item that fits perfectly could be an experience valuable enough to be worth what others might consider a high price for a simple knitted sweater.

\section{The production process}

One of the original purposes of the Knit on Demand project was to test complete garment technology so that the appropriate machinery could be purchased. However, it was considered too risky to invest in a complete garment machine for one research project, so existing fully fashioned and cut \& sew machines were used. During the development of the garments the research team decided whether to use only fully fashioned or only cut \& sew machines. The technologies offered different set-ups and placements of the CODP in the production line, as illustrated in Figure $\mathbf{5}$.

In theory, cut \& sew has the fastest order-to-delivery time, since panels can be knitted and kept in stock until a customer order arrives. Such a set-up would also lessen dependency on the manufacturer's available knitting capacity within the promised lead time, since the fabric has already been produced. Because the knitting factory also manufactures ordinary mass produced garments, sometimes the customized products must wait to be knitted.

Cut $\&$ sew technology is also flexible because any shape can be cut from the panels. It does, however, create more material waste than fully fashioned and complete garment machines; the panels are cut into pieces that must be sewn together, which requires available sewing capacity.

Before a fully fashioned garment can be produced it is programmed in a computerized design system connected to the knitting machine. Since the garment pieces cannot be knitted until there is a customer order, the fully fashioned technique is slightly slower from order to delivery than the cut $\&$ sew method-but only by one hour (because the cut $\&$ sew 
panels is knitted in advance and held in stock), which is trivial compared to the promised lead time of three weeks. However, the problem is not the lead time, but the available knitting capacity within the promised lead time.

In this project a trade-off was made between flexibility and the look of the garment, particularly the seams. Appearance was considered to be more important, and fully fashioned garments have neater seams where the body meets the arms. Therefore, fully fashioned knitting machines were used for most parts, but cut $\&$ sew was used on the neck. While there are several decoupling points in the supply chain, this paper focuses on the steps following the CODP. Figure 6 illustrates the Knit on Demand production process with lead times $(\mathrm{L} / \mathrm{T})$, set-up times $(\mathrm{S} / \mathrm{T})$, and standard allowed minutes (SAM). SAM is the time each operation takes, which differs from the actual lead time because it depends on the set-up time required.

The total value-adding time in the production process is 124 minutes. When set-up and waiting times are included, the lead time is 134.5 minutes. However, when the cost of the garment is calculated, the total time is presented in SAM. For example, the knitting step includes a 100 percent allowance to account for down time, set-up time, and problems that might occur with each new garment. Using SAM, the total lead time is 179.7 minutes.

\section{Delivery and customer satisfaction}

The total lead time between a customer order and product delivery is one to three weeks. Delivery from the factory to the store in Stockholm, or directly to the customer, takes one to two days. Before the customer receives the garment, labels are added and the customer is notified by phone or e-mail.

The target is to reduce the throughput time in the factory to less than five days, decreasing the total lead time to one week. To do this, production volume must increase to at least one garment per day. Ideally, a knitting machine can be dedicated to produce these garments during one specific day set aside for customized garment production. This would allow the operator to get a sense of the particular knitting machine being used. If a customer decides that the finished garment is not what was ordered, according to Swedish consumer law he or she cannot return the garment without proof that the product was not made according to the order specifications, e.g., the yarn colour was wrong. In such cases a new garment must be produced.

One concern was that customers would not be willing to pay the garment's price of between 1300 and 1600 SEK, depending on the model and add-ons. The customer can choose to pick up

\section{Cut \& Sew}

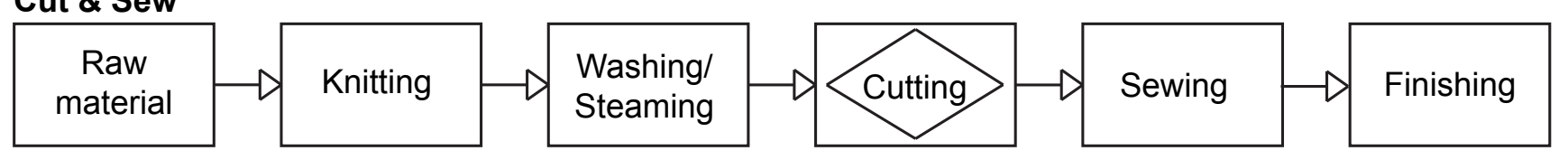

\section{Fully fashion/Integral knitting}

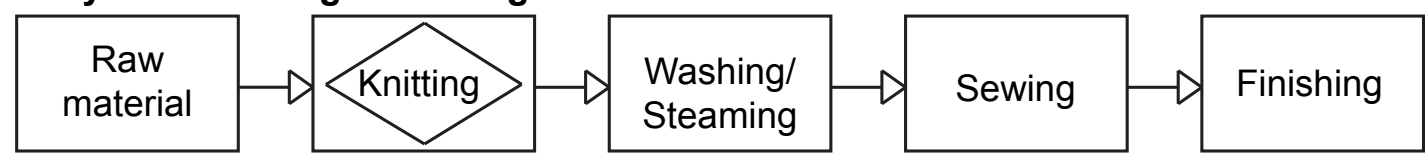

\section{Complete garment}

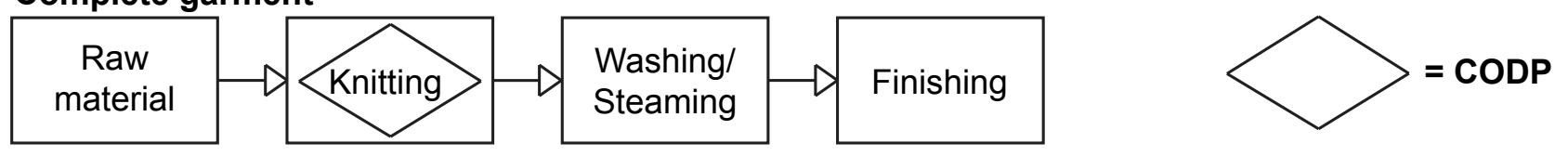

Figure 5. Production processes and the customer order decoupling point.

\section{Fully Fashion + Cut $\&$ Sew}

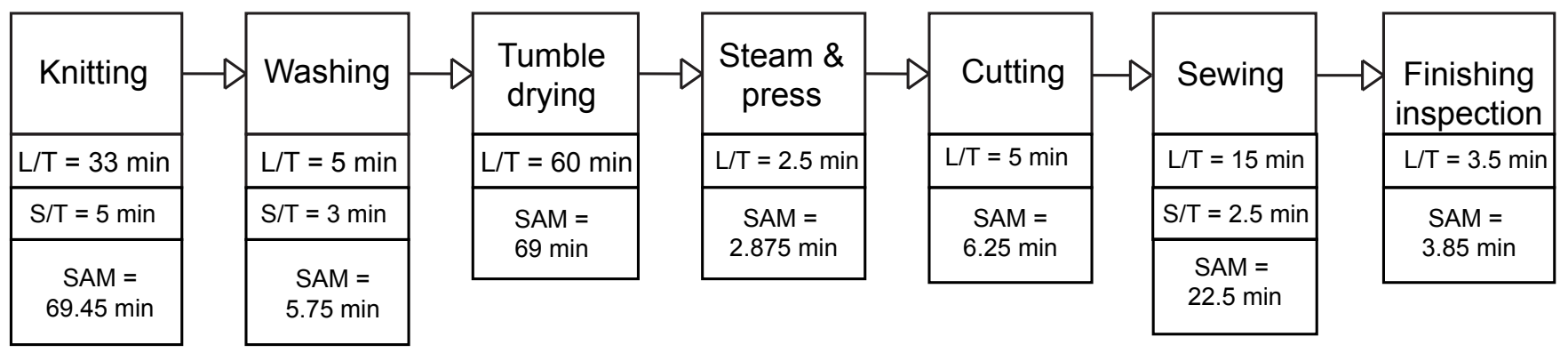

Figure 6. Process steps with lead times (L/T), set-up times (S/T), and standard allowed minutes (SAM). 
the garment at the store in Stockholm or have it sent by post; the delivery fee adds an additional 70 SEK. However, very few of the customers interviewed were concerned about price. They accepted a higher price as long as they received a unique or well-fitting garment.

The production cost of a customized V-neck garment is 265 SEK, about 60 SEK higher than that of an equivalent mass produced standard product. The wholesale price is 600 SEK, and it retails at 1400 SEK. Because the manufacturing cost of a mass customized garment is 25 percent higher than that of an equivalent mass produced standard item, the wholesaler's mark-up is what can be expected for a fashion garment: around 2.5 times the wholesale price. The cost of delivery from the producer to the store is 50 SEK per garment with the Swedish post.

\section{Knit on Demand in a logistics perspective}

The Knit on Demand concept fits Gilmore and Pine's definition of collaborative customization [23]. Customers may change both the appearance of the garment and its functionality, in this case the size. Collaborative customization cannot function properly without close customer involvement. Salvador et al. [24] describe such a system as hard customization, which requires a highly responsive supply chain. The fact that most customers in the study made size adjustments to the garments, even if small, demonstrates that there is a market for mass customized knitwear.

A combination of fully fashioned and cut \& sew knitting technologies offers the best balance between flexibility and economies of scale. Modularity is key to successful mass customization, and in this project all garments were customized from the same base module, which was adjusted according to the customer's measurements $[25,21]$. The products had to be high quality, as it was unaffordable to produce garments that might be returned due to defects. The customization process and design concept, along with the one-piece flow of garments through the production chain, increased product quality. Even though the Knit on Demand production processes did not perfectly match what Miltenburg [20] describes as one-piece flow, they shared common benefits such as high flexibility and product quality. However, drawbacks of mass customization include decreased productivity [38] and high manufacturing costs that result from the need for increased control in knitting operations.

The Knit on Demand supply chain is both lean and agile. Its manufacturing process is lean because it eliminates waste and time by only producing to meet actual customer demand, thereby reducing overproduction and the risk of unsold garments. The supply chain is also agile because it is extremely demand driven. In the customization process, a tailor listens to requests of the individual customer so that the company can meet each client's specific demands for design and fit. The high level of customer involvement, as well as the close collaboration between the retailer and the manufacturer, is a sign of agility. Customer orders can be changed rapidly to respond to customer requirements.
The position of the CODP in the production chain differs according to the knitting technology used. The cut $\&$ sew process has the fastest order-to-delivery time because the panels can be knitted and held in stock. The disadvantage is that customers must select panels from the inventory and cannot create their own designs, which is possible in the fully fashioned and complete garment alternatives. Cut \& sew is agile because it can quickly respond to a customer order, but the other processes are also deemed agile because they offer the client more design alternatives. If one knitting machine can be allocated for customized garments during one day per week in the factory, this production can be scheduled in advance. This system fits Mason-Jones's definition of a leagile supply chain [39-40], which is agile to respond to volatile customer demand downstream and lean using scheduled manufacturing in the production stage upstream.

\section{Conclusion}

One year of testing the Knit on Demand supply chain has yielded a number of conclusions. The following section discusses the most important findings from the perspective of supply chain management, along with suggestions for further research.

The Knit on Demand supply chain contains what may be called "profitable inefficiencies". Since the project was a start-up with a new business concept, the partners did not know the optimal design, production, and logistic solutions in advance. However, the production method chosen by the research team, knitting company, and retailer offered the best tradeoff between design flexibility, manufacturability, and customer satisfaction. Aesthetics received somewhat more attention than manufacturability and flexibility, as unattractive garments would not sell.

Why does it matter if this concept is lean, agile or leagile? A business's aim is to be profitable-a particular challenge in the fashion industry, where customer demand constantly changes. This volatile market requires an agile supply chain. At the same time, cost-effectiveness in garment production comes from a lean manufacturing philosophy that minimizes waste, whether of time or material.

The Knit on Demand project involved a garment producer with a lean manufacturing system and a retailer with agile individualized customer service during the design process. This leagile approach was well-suited to a fashion company selling customized knit products; it met customer demand for design and fit, with an acceptable delivery time and cost.

This study is the first to present a mass customization concept for knitted fashion products in a full-scale retailing and production environment in which customers design and buy actual garments. It reveals that customers purchase customized knitted garments in order to obtain a perfect fit and design, which they otherwise have difficulty finding.

One direction for further research would be to test the original idea of Knit on Demand by using a complete garment machine that makes ready-made items directly on the knitting machine. 
It may also be fruitful to determine how interested customers are in the design process and if they would like to see how the product is manufactured. People outside the industry rarely witness the inner workings of textile manufacture, and many customers may find it exciting to design their own garment and see it knitted.

\section{Acknowledgments}

The Knit on Demand project has been funded by the Knowledge Foundation in Sweden. The authors would like to express their appreciation to Ivanhoe $A B$ and SOMconcept $A B$ for participating in the project and for the help of many people at both companies. Portions of this work were presented at the MCP-Asia Pacific 2010 conference during November 6 to 8 , 2010, in Taipei, Taiwan.

\section{References:}

1. Mattila, H., King, R. and Ojala, N. (2002). Retail performance measures for seasonal fashion. Journal of Fashion Marketing and Management, Vol. 6, No. 4, pp. 340-351.

2. Cerruti, C. and Harrison, A. (2006). Agile supply chain in the fashion business. Supply Chain Practice, Vol. 8, No. 1, pp. 4-21.

3. Larsson, J. (2009). One-piece fashion. Demand driven supply chain management. Swedish School of Textiles. Thesis (licentiate). University of Borås, Sweden.

4. Pine, B. J. (1993). Mass Customisation: The New Frontier in Business Competition. Boston: Harvard University Press.

5. Piller, F. and Müller, M. (2004). A new marketing approach to mass customization. International Journal of Computer Integrated Manufacturing, Vol. 17, No. 7, pp. 583-593.

6. Huang, X., Kristal, M. M. and Schroeder, R. G. (2008). Linking learning and effective process implementation to mass customization capability. Journal of Operations Management, Vol. 26, No. 6, pp. 714-729.

7. Florida, R. (2002). The rise of the creative class. Washington Monthly, Vol. 34, No. 5, pp. 15-25.

8. Gilmore, J. H. and Pine, B. J. (2007). Authenticity: What Consumers Really Want. Boston: Harvard Business Publishing.

9. Pine II, B. J. and Gilmore, J. H. (1998). Welcome to the experience economy. Harvard Business Review, Vol. 76, No. 4, pp. 97-105.

10. Ulrich, P. V., Anderson-Connell, L. J. and Wu, W. (2003). Consumer co-design of apparel for mass customization. Journal of Fashion Marketing and Management, Vol. 7, No. 4, pp. 398-412.

11. Huffman, C. and Kahn, B. E. (1998). Variety for Sale: Mass Customization or Mass Confusion? Journal of Retailing, Vol. 74, No. 4, pp. 491-513.

12. CSCMP (2010). Supply chain management definitions, Council of Supply Chain Management Professionals. Supply Chain Management Terms and Glossary. http://cscmp.org/digital/glossary/glossary.asp [accessed 27/6/2012]
13. Christopher, M. (2000). The agile supply chain: Competing in volatile markets. Industrial Marketing Management, Vol. 29, No. 1, pp. 37-44.

14. Harrison, A. and van Hoek, R. (2008). Logistic Management and Strategy: Competing through the Supply Chain. Essex, England: Pearson Education Ltd.

15. Mason-Jones, R., Naylor, B. and Towill, D. (2000a). Lean, agile or leagile? Matching your supply chain to the marketplace. International Journal of Production Research, Vol. 38, No. 17, pp. 4061-4070.

16. Mason-Jones, R. and Towill, D. (1999). Total cycle time compression and the agile supply chain. International Journal of Production Economics, Vol. 62, No. 1-2, pp. 6173.

17. Christopher, M. and Towill, D. (2001). An integrated model for the design of agile supply chains. International Journal of Physical Distribution \& Logistics Management, Vol. 31, No. 4, pp. 235-246.

18. Liker, J. K. (2004). The Toyota Way. New York: McGrawHill.

19. Andersson, R., Eriksson, H. and Torstensson, H. (2006). Similarities and differences between TQM, six sigma and lean. The TQM Magazine, Vol. 18, No. 3, pp. 282-296.

20. Miltenburg, J. (2001). One-piece flow manufacturing on U-shaped production lines: A tutorial. IIE Transactions, Vol. 33, No. 4, pp. 303-321.

21. Pine II, B. J., Victor, B. and Boynton, A. C. (1993). Making mass customization work. Harvard Business Review, Vol. 71, No. 5, pp. 108-118.

22. Feitzinger, E. and Lee, H. L. (1997). Mass customization at Hewlett-Packard: The power of postponement. Harvard Business Review, Vol. 75, No. 1, pp. 116-121.

23. Gilmore, J. H. and Pine II, B. J. (1997). The four faces of mass customization. Harvard Business Review, Vol. 75, No. 1, pp. 91-102.

24. Salvador, F., Rungtusanatham, M. J. and Forza, C. (2004). Supply-chain configurations for mass customization. Production Planning \& Control, Vol. 15, No. 4, pp. 381-397.

25. Mikkola, J. H. and Skjøtt-Larsen, T. (2004). Supplychain integration: Implications for mass customization, modularization and postponement strategies. Production Planning \& Control, Vol. 15, No. 4, pp. 352-361.

26. Manuj, I. and Mentzer, J. T. (2008). Global supply chain risk management. Journal of Business Logistics, Vol. 29, No. 1, pp. 133-155.

27. Rudberg, M. and Wikner, J. (2004). Mass customization in terms of the customer order decoupling point. Production Planning \& Control, Vol. 15, No. 4, pp. 445-458.

28. Muffatto, M. and Roveda, M. (2002). Product architecture and platforms: A conceptual framework. International Journal of Technology Management, Vol. 24, No. 1, pp. 1-16.

29. Choi, W., and Powell, N. B. (2005). Three dimensional seamless garment knitting on $v$-bed flat knitting machines. Journal of Textile and Apparel Technology and Management, Vol. 4, No. 3, pp. 1-34.

30. Hunter, B. (2004). Complete garments, evolution or revolution? Knitting International, Vol. 111, No. 1321, pp. 20-22.

31. Yin, R. K. (2009). Case Study Research: Design and Methods. London. UK: Sage Publications. 
32. Näslund, D. (2002). Logistics needs qualitative research - especially action research. International Journal of Physical Distribution \& Logistics Management, Vol. 32, No. 5, pp. 321- 338.

33. Ellram, L. M. (1996). The use of the case study method in logistics research. Journal of Business Logistics, Vol. 17, No. 2, pp. 93-138.

34. Jick, T. D. (1979). Mixing qualitative and quantitative methods: Triangulation in action. Administrative Science Quarterly, Vol. 24, No. 4, pp. 602-611.

35. Hillman, M. and Pettersson, S.-M. (2010). Knit On Demand: A performance study of the concept mass customized knitted fashion garments. Swedish School of textiles. Thesis (BSc). University of Borås, Sweden.

36. Hines, P. and Rich, N. (1997). The seven value stream mapping tools. International Journal of Operations \& Production Management, Vol. 17, No. 1, pp. 46-64.
37. Larsson, J. (2011). Mass customised fashion: development and testing of a responsive supply chain for mass customised fashion garments. Swedish School of Textiles. Thesis (PhD). University of Borås, Sweden.

38. Alvan, A. and Aydin, A. O. (2009). The effects of mass customisation on productivity. International Journal of Mass Customisation, Vol. 3, No. 1, pp. 58-81.

39. Mason-Jones, R., Naylor, B., and Towill, D. R. (2000b). Engineering the leagile supply chain. International Journal of Agile Management Systems, Vol. 2, No. 1, pp. 54-61.

40. Mason-Jones, R. and Towill, D. R. (1999). Using the information decoupling point to improve supply chain performance. The International Journal of Logistics Management, Vol. 10, No. 2, pp. 13-26. 